\title{
Verapamil treatment after coronary angioplasty in patients at high risk of recurrent stenosis
}

Eike Hoberg, Rainer Dietz, Udo Frees, Hugo A Katus, Bernhard Rauch, Albert Schömig, Gerhard Schuler, Franz Schwarz, Harald Tillmanns, Josef Niebauer, Wolfgang Kübler

\begin{abstract}
Objective-To evaluate the efficacy of high-dose verapamil treatment $(240 \mathrm{mg}$ twice daily) in the prevention of angiographic restenosis after primary successful coronary angioplasty in patients at high risk of recurrent obstruction.

Design-A placebo controlled, double blind trial in which patients with stable angina pectoris and patients with unstable angina or non-Q wave infarction treated with $330 \mathrm{mg}$ aspirin and $75 \mathrm{mg}$ dipyridamole twice daily were randomised to a verapamil group or a control group. Follow up angiography was performed 6 months after angioplasty or sooner if signs of recurrent ischaemia developed.
\end{abstract}

Setting-University department of cardiology.

Patients -196 consecutive patients undergoing coronary angioplasty from the beginning of April 1987 to the end of March 1989 and meeting the selection criteria that included the presence of at least one of six predefined risk factors for restenosis. At the time of coronary angioplasty 113 patients had unstable angina or non- $Q$ wave infarction and 83 had stable angina pectoris.

Results-In 89 (91\%) patients in the verapamil group and in $83(85 \%)$ control patients follow up angiograms were available. The restenosis rate was lower in the verapamil group $(48 \cdot 3 \%)$ than in the placebo group (62.7\%) (odds ratio 0.56 , $95 \%$ confidence interval (CI) 0.303 to $1.025 \mathrm{p}=0.059$ ). Of the 172 patients in whom follow up angiograms were available, 24 (13 taking verapamil and 11 taking placebo) did not comply with the trial for more than 40 (34) days (mean (1 SD)). For the remaining 148 patients the restenosis rate was $47.4 \%$ in the verapamil group and $63.9 \%$ in the placebo group (odds ratio $0.52,95 \%$ CI 0.271 to $0.993, p=0.046)$. In the 97 patients with unstable angina or non- $Q$ wave infarction the restenosis rate was not significantly influenced by verapamil $(55.8 \%$ with verapamil $v 62.2 \%$ with placebo, odds ratio $0.77,95 \%$ CI 0.339 to $1.728, p=0.520$ ). In the 75 patients with stable angina pectoris the restenosis rate dropped from $63.2 \%$ with placebo to $37 \cdot 8 \%$ with verapamil (odds ratio $0.36,95 \%$ CI 0.137 to 0.917 , $\mathbf{p}=0.038)$.

Conclusion-The observed beneficial effect of high-dose verapamil treatment on the angiographic restenosis rate in patients with stable angina pectoris and at increased risk of recurrent obstruction requires confirmation in further prospective studies.

(Br Heart f 1994;71:254-260)

The primary success rate of coronary angioplasty has increased from $64 \%$ in the first series of Grüntzig et al ${ }^{1}$ to over $90 \%$ in experienced centres today. ${ }^{2}$ Serious complications of the procedure are rare and have declined during the past few years. ${ }^{34}$ Restenosis rates, however, remained constant, or even tended to increase as procedures were performed in patients with more complex lesions and in patients with multivessel disease. ${ }^{5-16}$ The recurrence of stenosis is the major limitation of coronary angioplasty, especially in patients at high risk of restenosis after initially successful coronary angioplasty.

Proliferation of smooth muscle cells in the media and their migration towards the intima of the vessel wall lead to the development of restenosis after coronary angioplasty. ${ }^{17}$ Experimental data indicate that verapamil inhibits this process. ${ }^{18-20}$ We have investigated the efficacy of verapamil in preventing restenosis in patients who are at increased risk for recurrent obstruction. Because chronic and acute ischaemic syndromes ${ }^{21}$ may respond differently to therapeutic interventions we studied the effect of verapamil on the development of restenosis in patients with stable angina pectoris and in patients with unstable angina or acute non- $Q$ wave infarction.

\section{Patients and methods}

PATIENTS

During the recruitment period, from the start of April 1987 to the end of March 1989, 1325 coronary angioplasty procedures were performed in 1076 patients at our laboratory. Primary success ( $\geqslant 20 \%$ reduction in diameter stenosis without major procedure-related complications within 48 hours) was achieved in $1418(91.4 \%)$ of the 1551 narrowings and occlusions attempted. All 981 patients with initially successful coronary angioplasty (patient-related primary success rate $=$ $91 \cdot 2 \%$ ) were screened for entry into the trial. Because of their possible interaction with verapamil, the decision of the treating physician to 
prescribe $\beta$ blockers or calcium antagonists (for example, for secondary prevention after myocardial infarction or for the treatment of arterial hypertension) excluded 215 patients. Further predefined criteria for exclusion were acute transmural myocardial infarction $(n=131)$, age $>70$ years $(n=51)$, an earlier revascularisation procedure $(n=45)$, severe concomitant disease $(n=18)$, congestive heart failure $(n=6)$, bradycardia $<50$ beats $/ \min (n=1)$, and other reasons $(n=25)$. Of the remaining 489 patients 308 agreed to participate in the trial, but only 196 patients presented with at least one of the following predictors for restenosis that were defined according to clinical studies reported before 1986: diabetes mellitus, ${ }^{822} 23$ multivessel coronary artery disease, ${ }^{23}{ }^{24}$ total or subtotal occlusion of the dilated segment, ${ }^{8212526}$ eccentric narrowing, ${ }^{23}$ proximal lesion of the left anterior descending coronary artery, ${ }^{5223}$ and residual stenosis of $\geqslant 30 \% .572223$ These patients were randomly assigned either to placebo $(n=98)$ or to treatment with verapamil $(n=98)$. To allow separate analysis of restenosis rates in chronic and acute ischaemic syndromes, patients with stable angina pectoris $(n=83)$ and patients with unstable angina or non- $Q$ wave infarction $(n=113$ ) were randomised as different subgroups. The unstable angina and non- $Q$ wave infarction subgroup included 25 patients with recent onset angina, 45 patients with crescendo angina, eight patients with angina at rest, 31 patients with post-infarction angina, and four patients with non-transmural myocardial infarction within the last week.

\section{STUDY PROTOCOL}

Enrolled patients were randomly assigned in a double blind fashion to either the placebo group or the treatment group. The study drugs were provided for 7 months by the manufacturer as uniform tablets in numbered lots, beginning with sample No 1 for patients with stable angina pectoris and beginning with sample No 260 for patients with unstable angina or non-Q wave infarction. The patients received 2 months' supply of the study medication at hospital discharge. Two outpatient examinations were scheduled for 2 and 4 months after coronary angioplasty. On these occasions, the patient's history was taken and a 12 lead electrocardiogram was recorded. In addition, adherence to drug treatment was checked by pill counts, and the drug supply for the next 2 months was handed out to the patients. Six months after enrolment the patients were admitted to hospital for follow up angiography. Repeat angiography was performed early if symptoms of recurrent myocardial ischaemia suggested restenosis. The variables evaluated in the trial were presence or absence of angiographic restenosis, cardiac death, and myocardial infarction in the area supplied by the target coronary vessel. If early follow up angiography did not confirm the clinical evidence of recurrence of obstruction, the patient continued to take the initially assigned medication, until final follow up angiography was performed at 6 months after enrolment. The study protocol was approved by the local ethics committee of the university of Heidelberg.

\section{ANGIOPLASTY PROCEDURE}

Before coronary angioplasty all patients were routinely premedicated with aspirin $330 \mathrm{mg}$ plus dipyridamole $75 \mathrm{mg}$ twice daily. Heparin (15000 units) was injected intravenously just before the procedure. Dilatation was performed by a steerable technique with $8 F$ guiding catheters. Angiograms were filmed in at least two orthogonal views before and after the angioplasty. Nitrates and calcium antagonists were not routinely given during the procedure.

\section{POST-PROCEDURE MEDICATION}

Heparin was infused intravenously at a rate of 1250 units per hour for 4-16 hours. After the groin sheath was removed 4-6 hours later, 7500 units heparin was given subcutaneously three times a day for the next 24 hours. Antiplatelet therapy with aspirin $(330 \mathrm{mg}$ ) and dipyridamole $(75 \mathrm{mg}$ ) was given twice a day for 6 months. Patients who entered the trial were given either verapamil $240 \mathrm{mg}$ (Isoptin RR, Knoll, Ludwigshafen, Germany) twice daily or placebo twice daily, starting on the first to third day after coronary angioplasty, and ending on the morning before follow up angiography. Concomitant treatment with $\beta$ blockers or calcium antagonists for more than 3 days resulted in the exclusion of the patient. Other medication could be prescribed by the private physician.

\section{MEASUREMENT OF CORONARY STENOSIS}

Films were evaluated by two independent experts who were blinded to the identity and to the treatment of the patients. Measurements taken with computerised calipers at the smallest luminal diameter were compared with the closest normal segment and were averaged in two projections. The degree of stenosis expressed as the percentage reduction in luminal diameter was calculated as the mean of the measurements of both experts. We took great care to use the same projections for the analysis of all three angiograms for each patient. Restenosis was defined as $\geqslant 50 \%$ loss of the initial gain in stenosis reduction (National Heart, Lung and Blood Institute (NHLBI) criterion IV).

The mean difference in percentage reduction in luminal diameter before coronary angioplasty between both observers was $3 \cdot 7$ $(2 \cdot 7) \%$, corresponding to an interobserver variability (difference of the two measurements divided by the mean value $\times 100$ ) of $4.5(3.6) \%$. Because computerised angiographic analysis with an automatic edge detection algorithm became available only after much of a the trial had been completed we retrospectively validated our mode of measurement in a random sample of 24 follow up angiograms ( 12 from the verapamil group and 12 from the placebo group). A third independent expert, who was blinded to the identity 
and the treatment of the patients, compared the results of the callipers method with the results of the Kontron Mipron image-processing system in combination with an automatic edge detection algorithm as described in detail earlier. ${ }^{27}$ The correlation for the two methods was $r=0.92(p<0.0001)$ with a slope of 0.88 and a $y$ intercept of $1.55 \%$.

\section{STATISTICAL ANALYSIS}

We estimated that we needed to study at least 150 patients, assuming that a decrease of $>50 \%$ in restenosis rate is clinically relevant. Because we selected patients at high risk, the restenosis rate in the placebo group was assumed to exceed $45 \%$. With a presumed drop-out rate of $25 \%, 200$ patients needed to enter the study to allow for a sufficient statistical power (alpha $=0.05$, beta $=0.2$ ) in a twotailed test and for an efficacy analysis (compliant patients with available control angiography) in addition to a modified intention-to-treat analysis (all enrolled patients in whom follow up angiography was available). Based on experience in 1986 we decided on a recruitment period of two years.

We examined the homogeneity of the patient groups in terms of age, sex, demographic factors, history, and angiographic factors by appropriate parametric and non-parametric tests. The odds ratio and its 95\% confidence interval were used to describe the relative risk for restenosis in the treatment group. Probabilities were regarded as statistically significant at the 0.05 level. Unless otherwise indicated, values are given as the mean (1 SD).

\section{Results}

BASELINE CHARACTERISTICS

Table 1 shows the clinical and angiographic characteristics of the treatment group and the placebo group. The incidence of diabetes mellitus was low and unbalanced $(14 \%$ in the verapamil group $v 4 \%$ in the placebo group, $p<0.05)$. None of the other baseline patient characteristics or the characteristics of the dilated lesion in the two groups differed significantly. The mean number of risk factors for restenosis was $2.5(1.0)$ in the verapamil

Table 1 Characteristics related to the patient and lesion in 98 patients assigned to the treatment group and 98 patients assigned to the placebo group

\begin{tabular}{|c|c|c|}
\hline Characteristic & $\begin{array}{l}\text { Verapamil } \\
(n=98)\end{array}$ & $\begin{array}{l}\text { Placebo } \\
(n=98)\end{array}$ \\
\hline $\begin{array}{l}\text { Patient related: } \\
\text { Age } \\
\text { Male (\%) } \\
\text { Diabetes (\%) } \\
\text { Arterial hypertension by history (\%) } \\
\text { Hyperlipidaemia by history (\%) } \\
\text { Peripheral arterial disease (\%) } \\
\text { Previous myocardial infarction (\%) } \\
\text { Multivessel coronary artery disease (\%) }\end{array}$ & $\begin{array}{l}54 \cdot 6(7 \cdot 7) \\
79 \\
14^{\star} \\
40 \\
55 \\
12 \\
46 \\
37\end{array}$ & $\begin{array}{l}54 \cdot 6(7 \cdot 0) \\
85 \\
4^{\star} \\
51 \\
50 \\
8 \\
40 \\
42\end{array}$ \\
\hline $\begin{array}{l}\text { Lesion related: } \\
\text { Proximal lesion of the left anterior } \\
\text { descending coronary artery (\%) } \\
\text { Eccentric narrowing (\%) } \\
\text { Subtotal/total occlusion (\%) } \\
\% \text { Stenosis before angioplasty (mean (ISD)) } \\
\% \text { Stenosis after angioplasty (mean (ISD)) } \\
\text { Residual lesion } \geqslant 30 \%(\%)\end{array}$ & $\begin{array}{l}62 \\
58 \\
9 \\
85 \cdot 7(9 \cdot 6) \\
34 \cdot 0(13 \cdot 1) \\
66\end{array}$ & $\begin{array}{l}68 \\
47 \\
12 \\
85 \cdot 9(8 \cdot 6) \\
35 \cdot 0(15 \cdot 4) \\
67\end{array}$ \\
\hline
\end{tabular}

group and $2.4(0.9)$ in the placebo group (NS).

\section{ADHERENCE TO THE STUDY PROTOCOL}

Eighty nine patients in the verapamil group (91\%) and 83 patients in the placebo group (85\%) had follow up angiography and were analysed on the modified intention-to-treat basis. Despite the availability of a follow up angiogram, 13 patients in the verapamil group and 11 patients in the placebo group were excluded from the efficacy analysis because they stopped taking the prescribed study medication after 40 (34) days and 41 (55) days respectively. Verapamil-related adverse side effects caused the withdrawal of three patients (constipation, dizziness, rise in circulating liver enzymes). Other reasons for dropping out were similar in patients on verapamil and in patients on placebo: in both groups four patients refused to participate in the trial after discharge from the hospital. In five patients in the verapamil group and in four patients in the placebo group $\beta$ blockers or calcium antagonists were given by the private physician instead of the study medication. Tachycardia or high blood pressure or both were the reasons for stopping participation for three patients in the placebo and for one patient in the verapamil group, who had been on $\beta$ blocker therapy before coronary angioplasty.

Death or myocardial infarction did not occur in either group during the study period. Twenty patients in the verapamil group and 25 patients in the placebo group developed signs of recurrent ischaemia and early repeat angiography confirmed restenosis after 83 (46 days) (verapamil group) and after 73 (28) days (placebo group) after coronary angioplasty (NS). In one other patient who presented with recurrent angina, coronary angiography was performed 6 weeks after dilatation but it showed a sustained success of the procedure. According to the study protocol this patient continued to take the assigned study medication and underwent repeat angiography at 6 months after enrolment.

\section{RESTENOSIS}

The mean diameter stenosis in the 172 patients for whom follow up angiograms were available decreased from $86 \cdot 4(8 \cdot 5) \%$ before coronary angioplasty to $34.8(14.5) \%$ immediately after. There were no significant differences between the two groups. At follow up angiography the mean coronary obstruction had increased by $26.9(24.6) \%$ in the verapamil group and by $31.9(29.0) \%$ in the placebo group $(p=0 \cdot 11)$. In the 172 patients with a follow up angiogram restenosis occurred in $48.3 \%$ in the verapamil group and $62.7 \%$ in the placebo group (odds ratio 0.56 , $95 \%$ CI 0.303 to $1.025, p=0.059$ ). In the 148 patients, who actually received the treatment, the difference in restenosis rate between the two groups was statistically significant (odds ratio $0.52,95 \%$ CI 0.271 to $0.993, p=0.046)$. The cumulative distribution curves of the lesions before dilatation and 
Figure 1 Cumulative distribution curves for coronary obstructions before coronary angioplasty (PTCA), immediately after, and at follow up in 89 patients assigned to the verapamil group and in 83 patients assigned to the placebo group.

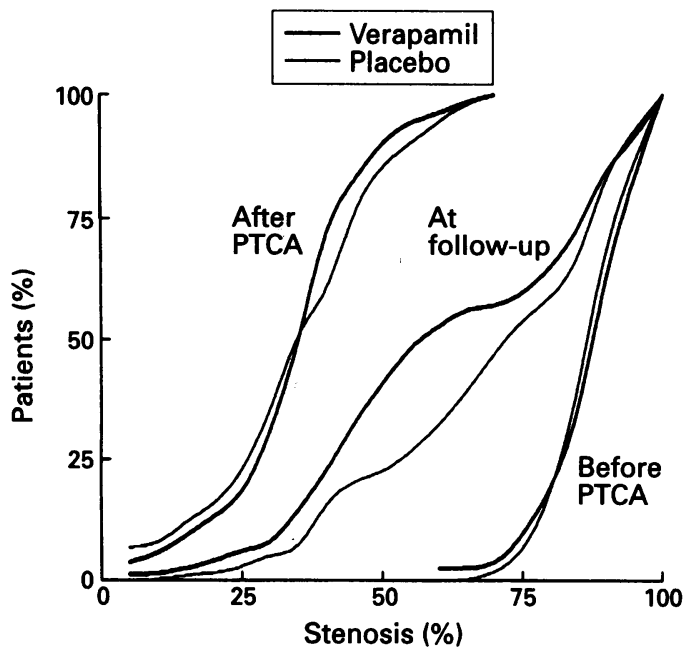

immediately after coronary angioplasty were similar in the two groups (fig 1). At follow up angiography the lesion distribution curve of the verapamil group showed a shift to the left indicating a higher incidence of low degree lesions compared with the placebo group (fig 1).

\section{STABLE ANGINA PECTORIS COMPARED WITH UNSTABLE ANGINA OR NON-Q WAVE INFARCTION}

Baseline demographic data and lesion-related characteristics were similar in the verapamil groups and the placebo groups with stable angina $(n=83)$ and unstable angina or non$Q$ wave infarction $(n=113)$ (table 2$)$. In the 97 patients with unstable angina or non-Q

Table 2 Characteristics related to the patient and lesion in 113 patients with unstable angina or non- $Q$ wave infarction and in 83 patients with stable angina pectoris

\begin{tabular}{|c|c|c|c|c|}
\hline \multirow[b]{2}{*}{ Characteristic } & \multicolumn{2}{|c|}{ Unstable angina } & \multicolumn{2}{|l|}{ Stable angina } \\
\hline & $\begin{array}{l}\text { Verapamil } \\
(n=57)\end{array}$ & $\begin{array}{l}\text { Placebo } \\
(n=56)\end{array}$ & $\begin{array}{l}\text { Verapamil } \\
(n=41)\end{array}$ & $\begin{array}{l}\text { Placebo } \\
(n=42)\end{array}$ \\
\hline $\begin{array}{l}\text { Patient related: } \\
\text { Age (y) } \\
\text { Male (\%) } \\
\text { Diabetes (\%) } \\
\text { Arterial hypertension by history (\%) } \\
\text { Hyperlipidaemia by history (\%) } \\
\text { Peripheral arterial disease (\%) } \\
\text { Previous myocardial infarction (\%) } \\
\text { Multivessel coronary artery disease (\%) }\end{array}$ & $\begin{array}{l}54 \cdot 0(7 \cdot 8) \\
77 \\
18 \\
47 \\
54 \\
12 \\
44 \\
37\end{array}$ & $\begin{array}{l}54 \cdot 8(6 \cdot 5) \\
82 \\
7 \\
54 \\
54 \\
9 \\
48 \\
41\end{array}$ & $\begin{array}{l}55 \cdot 2(7 \cdot 6) \\
80 \\
10 \\
29 \\
56 \\
12 \\
49 \\
37\end{array}$ & $\begin{array}{l}54 \cdot 3(7 \cdot 6) \\
88 \\
0 \\
48 \\
45 \\
7 \\
29 \\
43\end{array}$ \\
\hline $\begin{array}{l}\text { Lesion related: } \\
\text { Proximal lesion of the left anterior } \\
\text { descending coronary artery (\%) } \\
\text { Eccentric narrowing (\%) } \\
\text { Subtotal/total occlusion (\%) } \\
\% \text { Stenosis before angioplasty } \\
\text { (mean (ISD)) }\end{array}$ & $\begin{array}{l}70 \\
60 \\
7 \\
85 \cdot 3(8 \cdot 8)\end{array}$ & $\begin{array}{l}70 \\
41 \\
14 \\
86 \cdot 9(8 \cdot 6)\end{array}$ & $\begin{array}{l}51 \\
56 \\
12 \\
86 \cdot 3(10 \cdot 7)\end{array}$ & $\begin{array}{l}67 \\
55 \\
10 \\
84 \cdot 6(8 \cdot 6)\end{array}$ \\
\hline $\begin{array}{l}\text { \% Stenosis after angioplasty } \\
\text { (mean (ISD)) }\end{array}$ & $35 \cdot 1(12 \cdot 4)$ & $36 \cdot 0(17 \cdot 5)$ & $32 \cdot 4(13.9)$ & $33 \cdot 7(12 \cdot 1)$ \\
\hline Residual lesion $\geqslant 30 \%(\%)$ & 72 & 64 & 59 & 71 \\
\hline
\end{tabular}

Table 3 Results of the modified intention-to-treat analysis (all patients with available control angiography) and of the efficacy analysis (compliant patients for whom follow up angiograms were available in the prospectively stratified subgroups of stable angina pectoris and unstable angina or non $Q$ wave infarction.

\begin{tabular}{|c|c|c|c|c|}
\hline & \multicolumn{2}{|c|}{ Restenosis rate (\%) } & \multirow[b]{2}{*}{ Odds ratio $(95 \%$ CI $)$} & \multirow[b]{2}{*}{$p$} \\
\hline & Verapamil & Placebo & & \\
\hline $\begin{array}{l}\text { Intention-to-treat: } \\
\text { Unstable angina }(n=97) \\
\text { Stable angina }(n=75)\end{array}$ & $\begin{array}{l}55 \cdot 8 \\
37 \cdot 8\end{array}$ & $\begin{array}{l}62 \cdot 2 \\
63 \cdot 2\end{array}$ & $\begin{array}{l}0.77(0.339 \text { to } 1.728) \\
0.36(0.137 \text { to } 0.917)\end{array}$ & $\begin{array}{l}0.52 \\
0.038\end{array}$ \\
\hline $\begin{array}{l}\text { As treated: } \\
\text { Unstable angina }(\mathrm{n}=81) \\
\text { Stable angina }(\mathrm{n}=67)\end{array}$ & $\begin{array}{l}60 \cdot 5 \\
30 \cdot 3\end{array}$ & $\begin{array}{l}65 \cdot 8 \\
61 \cdot 8\end{array}$ & $\begin{array}{l}0.80(0.316 \text { to } 1.992) \\
0.27(0.096 \text { to } 0.754)\end{array}$ & $\begin{array}{l}0.62 \\
0.01\end{array}$ \\
\hline
\end{tabular}

wave infarction in whom follow angiography was available high-dose verapamil treatment did not significantly influence the development of restenosis after coronary angioplasty (restenosis rates $\mathbf{5 5 . 8 \%}$ with verapamil and $62 \cdot 2 \%$ with placebo, $\mathrm{p}>0 \cdot 15$ ) (table 3 ). The cumulative distribution curve of the lesions at follow up angiography showed a slight shift to the left in the verapamil group compared with the placebo group (fig 2). Efficacy analysis of the 81 compliant patients gave similar results (table 3).

In contrast to the group with unstable angina, in the 75 patients with stable angina pectoris and a follow up angiogram the restenosis rate decreased significantly from $63.2 \%$ with placebo to $37 \cdot 8 \%$ with verapamil (odds ratio $0.36,95 \%$ CI $0.137-0.917, \mathrm{p}=$ 0.038 ) (table 3 ). The cumulative distribution curve of the lesions at follow up was shifted to

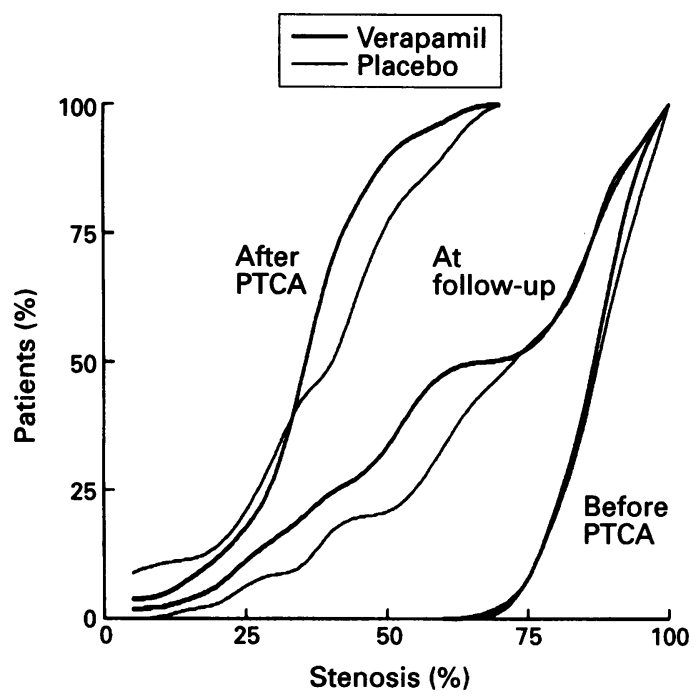

Figure 2 Cumulative distribution curves for coronary obstructions before coronary angioplasty (PTCA), immediately after, and at follow up in 97 patients (52 assigned to the verapamil group, 45 assigned to the placebo group) with unstable angina pectorison or non- $Q$ wave infarction and with follow up angiograms.

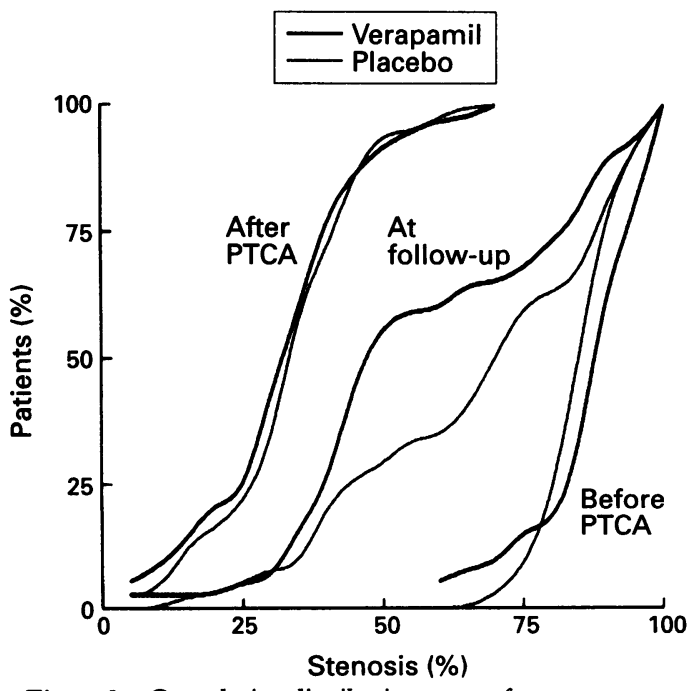

Figure 3 Cumulative distribution curves for coronary obstructions before coronary angioplasty (PTCA), immediately after, and at follow up in 75 patients (37 assigned to the verapamil group, 38 assigned to the placebo group) with stable angina pectoris and with follow up angiograms. 
the left in the verapamil group compared with the placebo group. The separation of the curves was most pronounced for reductions in luminal diameter of $40-70 \%$ (fig 3 ). Efficacy analysis of the 67 patients with stable angina treated with verapamil showed a decrease in restenosis rate by high dose verapamit treatment from $61.8 \%$ with placebo to $30.3 \%$ (odds ratio $0.2795 \%$ CI $0.96-0.754, p=$ 0.010 ).

\section{Discussion}

We found that high dose verapamil treatment reduced the restenosis rate in patients with stable angina pectoris but not in patients with unstable angina or non- $Q$ wave infarction. We studied only patients at increased risk for restenosis so it may be that the beneficial effect of verapamil is limited to this group.

COMPARISON WITH OTHER CLINICAL STUDIES

Three earlier trials have not shown that calcium channel blockers have a beneficial effect on restenosis rate after coronary angioplasty. Corcos et al investigated the influence of 90 $\mathrm{mg}$ diltiazem three times daily in a prospective randomised trial including 92 patients without variant angina or previous coronary bypass surgery..$^{12}$ Although the restenosis rate (defined as $\geqslant 70 \%$ coronary obstruction at follow up angiography) was lower in the diltiazem group (15\%) than in the control group $(22 \%)$, this difference was not statistically significant. More recently O'Keefe and colleagues reported on a randomised trial evaluating the effect of a higher dose of diltiazem (mean $329 \mathrm{mg} /$ day) in 201 patients without evolving myocardial infarction. ${ }^{13}$ Follow up angiography at one year was obtained in $60 \%$ of the patients. It showed no significant difference between the restenosis rates in the diltiazem (36\%) and placebo groups (32\%).

Whitworth et al investigated the influence of nifedipine on the development of restenosis in 241 patients without documented coronary artery spasm. ${ }^{11}$ At a dose of $40 \mathrm{mg}$ daily this calcium antagonist did not reduce the restenosis rate after coronary dilatation $(28 \%$ in the nifedipine group $v 29.5 \%$ in the placebo group). Differences in study design may account for conflicting results of these previous studies and the present trial.

Because we selected patients in whom the risk of restenosis was high the subsequent event rate was high too. This increased the statistical power of the study for detecting a possible beneficial effect of the treatment. In the diltiazem trial of Corcos $e t a l_{, 2}$ the small sample size combined with a low event rate, based on $\geqslant 70 \%$ stenosis at follow up angiography as the definition of restenosis, may account for the result not being statistically significant despite of a reduction of one third in restenosis.

We used a high dose of verapamil because experimental data suggested that calcium blockers had an anti proliferative effect only at high plasma concentrations. The fact that ver- apamil treatment was stopped because of drug-specific side effects in only three patients indicates that treatment with $240 \mathrm{mg}$ verapamil in slow release form twice daily is practicable and safe. The results of cell culture experiments indicated that the choice of calcium antagonist may be relevant. Verapamil was a more potent inhibitor of the proliferation of smooth muscle cells than nifedipine or diltiazem. ${ }^{19}$

The prospective stratification of patients into groups with stable angina and unstable angina or non- $Q$ wave infarction allowed us to detect the selective inhibitory effect of verapamil treatment on the restenosis rate in patients with stable angina pectoris only. Earlier studies were not designed to detect any selective effects in stable and unstable angina.

\section{POSSIBLE MECHANISM OF ACTION}

Proliferation and migration of medial smooth muscle cells into the intima of the vessel wall are assumed to play major parts in the pathogenesis of restenosis after coronary angioplasty. ${ }^{17} 28$ This process is mediated by platelet-derived growth factor and other proteins with similar or supplementary mitogenic effects. ${ }^{29}$ According to recent experiments with vascular smooth muscle cells in culture, calcium antagonists show a concentration-dependent inhibitory effect on several actions mediated by platelet-derived growth factor, including cell proliferation and an increase in the cytoplasmic concentration of free calcium. ${ }^{19}$ These findings accord with animal studies that showed inhibition of smooth muscle cell proliferation by calcium antagonists after localised arterial injury. ${ }^{30}{ }^{31}$ Most smooth muscle cell proliferation seems to be completed within 10 days after injury of the vessel wall ${ }^{32}$ The beneficial effect of verapamil on the restenosis rate after coronary angioplasty that we saw may therefore be caused by an inhibitory effect at this early stage of restenosis development.

The response to verapamil treatment depends on the clinical manifestation of coronary artery disease at the time of angioplasty: in unstable angina pectoris, the rupture of atherosclerotic plaques may initiate a cascade of events resulting in proliferative lesion properties that differ from those of fixed lesions in stable angina when the vessel wall is injured during coronary angioplasty. Treatment after dilatation will not affect the early stages of proliferation in most patients with unstable angina pectoris whereas it will in patients with stable angina.

\section{LIMITATIONS OF THE STUDY}

We used computerised callipers to measure the percentage diameter reduction. This method is more precise than visual estimation, and in the present trial the interobserver variability was $<5 \%$. In recent studies, however, computerised angiographic analysis was preferred, because despite some limitations it may give more a reproducible and objective measure of luminal diameter narrowing. ${ }^{33}$ It 
seems unlikely that the result of the present study depends on the mode of measurement: the retrospective analysis of a subset of 24 follow up angiograms by a third independent expert showed a correlation at $r=0.92$ between the computerised calipers method used throughout the present study and the Kontron Mipron image-processing system with an automatic edge detection algorithm. Because our study was a prospective, randomised and double-blinded trial with the measurement of each lesion performed blind by two experts, the number and extent of measurement errors are likely to be similar in the treatment and placebo groups. Furthermore, cumulative distribution curves of the lesions confirmed the results obtained by the calculation of restenosis rates (figs 1-3). Nevertheless, our data need to be confirmed in a prospective trial using computerised angiographic measurement of absolute luminal diameter.

A limitation of the study design is the time at which medication started. Because patients were enrolled only after successful coronary angioplasty, treatment started on the first to third day after the procedure. Experimental studies, however, indicate that restenosis begins to develop within the first days after injury to the vessel wall. ${ }^{32}$ Earlier treatment with verapamil might have had a more pronounced effect on the restenosis rate.

To increase the number of events (recurrent obstructions) only patients at high risk for restenosis were enrolled into the present trial and the results only apply to this subgroup of coronary angioplasty patients. The restenosis rate in the placebo group was much higher than the rate of $45 \%$, which was assumed for the estimation of the minimum sample size. This high restenosis rate is not typical of the catheter laboratory at the University of Heidelberg: the restenosis rate in unselected patients was $28 \%$ in those with stable angina and $38 \%$ in those with unstable angina in a previous series of 328 patients in the same laboratory. ${ }^{34}$ The selection of patients at high risk for recurrent obstruction may not only explain the high restenosis rate in the present trial but also the similar recurrence rates in patients with stable angina and those with unstable angina in the placebo group. The calculated rate of restenosis depends on the definition applied. According to a comparative study of Serruys $e t a^{35}$ the use of NHLBI criterion IV, which was prospectively selected for the present trial, results in higher restenosis rates than other criteria such as $>50 \%$ stenosis at follow up angiography or NHLBI criteria I, II, or III. The cumulative distribution curves at follow up showed a similar treatment effect on restenosis rates. In the present study the difference between the placebo group and the varapamil group in patients with stable angina pectoris was most pronounced for coronary obstructions of about $50 \%$. The treatment effect would have been missed by the use of NHLBI criterion II ( $\geqslant 70 \%$ stenosis at follow up), which was applied by Corcos and colleagues to the evaluation of dilitiazem treatment $^{12}$ (see figs 1 and 2).

IMPLICATIONS OF THE TRIAL

Aspirin has been shown to reduce the incidence of myocardial infarction early after successful coronary angioplasty, when the risk of thrombus formation at the site of the injured vessel is high. ${ }^{36}$ The restenosis rate at 6 months after the procedure, which seems to depend largely on the proliferation and migration of medial smooth cells, obviously cannot be influenced by aspirin. ${ }^{36}{ }^{37}$ The observed beneficial effect of verapamil on the angiographic restenosis rate in patients with stable angina may be due to the inhibition of this process which is mediated by growth factor. Hence combined medication with aspirin and verapamil in the early stage and the medication with verapamil alone thereafter may be effective during the first 4 months after coronary angioplasty in patients with stable angina pectoris. But before such an approach can be recommended the decrease in angiographic restenosis rate that we found was associated with treatment with a calcium antagonist needs to be confirmed in other studies.

We thank Sabine Lackner, RA for expert assistance. This study was supported by a grant from the Knoll Company, which provided the drugs for active treatment and the placebo. The study was conducted, analysed, and interpreted indepenThe study was conducted,
dently of the company.

1 Grüntzig A, Senning A, Siegenthaler WE. Nonoperative dilatation of coronary artery stenosis. Percutaneous transluminal coronary angioplasty. $N$ Engl f Med 1979; 301:61-8.

2 Block PC. Restenosis after percutaneous transluminal coronary angioplasty-anatomic and pathophysiological coronary angioplasty-anatomic and pathophysio

3 Simpfendorfer C, Belardi J, Bellamy G, Galan K, Franco I, Hollman J. Frequency, management and follow-up of patients with acute coronary occlusions after percutaneous transluminal coronary angioplasty. $A m \mathcal{F}$ Cardiol 1987;59:267-9.

4 Talley JD, Weintraub WS, Roubin GS, et al. Failed elective percutaneous transluminal coronary angioplasty requiring coronary artery bypass surgery. Circulation 1990;82:1203-13.

5 Leimgruber PP, Roubin GS, Hollmann J, et al. Restenosis after successful coronary angioplasty in patients with sinafter successful coronary angioplasty in patien

6 Kaltenbach M, Kober G, Scherer D, Vallbracht C. Recurrence rate after successful coronary angioplasty. Eur Heart $\mathcal{F}$ 1985;6:276-81.

7 Levine S, Ewels CJ, Rosing DR, Kent KM. Coronary angioplasty: clinical and angiographic follow-up. $A m \mathrm{f}$ Cardiol 1985;55:673-7.

8 Holmes DR, Vlietstra RE, Smith HC, et al. Restenosis after percutaneous transluminal coronary angioplasty (PTCA): a report from the PTCA Registry of the National Heart, Lung, and Blood Institute. Am $\mathcal{F}$ Cardiol National Heart, Lung

9 Mabin TA, Holmes DR Jr, Smith HC, et al. Follow-up clinical results in patients undergoing percutaneous transluminal coronary angioplasty. Circulation 1985; 71:754-60.

10 Bertrand ME, LeBranche JM, Thieuleux FA, Fourrier JL, Traisnel G, Asseman P. Comparative results of percutaneous transluminal coronary angioplasty in patients with dynamic versus fixed coronary stenosis. $\mathcal{F} \mathrm{Am}$ Coll Cardiol 1986;8:504-8.

11 Whitworth HB, Roubin GS, Hollman J, et al. Effect of nifedipine on recurrent stenosis after percutaneous transluminal coronary angioplasty. $f \mathrm{Am}$ Coll Cardiol 1986;8:1271-6.

12 Corcos T, David PR, Val PG, et al. Failure of diltiazem to prevent restenosis after percutaneous transluminal coronary prevent restenosis after percutaneous translumin
angioplasty. Am Heart $\mathcal{F} 1985 ; 109: 926-31$.

13 O'Keefe JH, Giorgi LV, Hartzler GO, Good TH, Ligon RW, Webb DL, McCallister BD. Effects of diltiazem on complications and restenosis after coronary angioplasty. $A m$ f Cardiol 1991;76:373-6.

14 Nobuyoshi M, Kimura T, Nosaka H, et al. Restenosis after successful percutaneous transluminal coronary angioplasty: serial angiographic follow-up of 229 patients. $\ngtr$ Am Coll Cardiol 1988;12:616-23.

15 Lambert M, Bonan R, Cote G, et al. Multiple coronary 
angioplasty: A model to discriminate systemic and procedural factors related to restenosis. $f$ Am Coll Cardiol 1988;12:310-4.

16 Vandormael MG, Deligonul U, Kern MJ, et al. Multilesion coronary angioplasty: clinical and angiographic follow-up. $f$ Am Coll Cardiol 1987;10:246-52.

17 Liu MW, Roubin GS, King SB III. Restenosis after coronary angioplasty. Potential biologic determinants and role of intimal hyperplasia. Circulation 1989;79:1374-87.

18 Stein $O$, Halperin G, Stein Y. Long-term effects of verapamil on aortic smooth muscle cells cultured in the prespamil on aortic smooth muscle cells cultured in the presence of hyperch

19 Block LH, Emmons LR, Vogt E, Sachinidis A, Vetter W, Hoppe J. $\mathrm{Ca}^{2+}$-channel blockers inhibit the action of recombinant platelet-derived growth factor in vascular smooth muscle cells. Med Sci 1989;86:2388-92.

20 Orekhov AN, Tertov VV, Khashimov KA, Kudryashov SA, Smirnov VN. Antiatherosclerotic effects of verapamil in primary culture of human aortic intimal cells. $f$ Hypertens 1986;4(suppl 5):S153-5.

21 Sherman CT, Litvack F, Grundfest W, et al. Coronary angioscopy in patients with unstable angina pectoris. $N$ Engl F Med 1986;315:913-9.

22 Hollman J, Galan K, Franco I, Simpfendorfer C, Fatica K, Beck G. Recurrent stenosis after coronary angioplasty [abstr] $\mathcal{F}$ Am Coll Cardiol 1986;7:20.

23 Mata LA, Bosch X, David PR, Rapold HJ, Corcos T, Bourassa MG. Clinical and angiographic assessment 6 months after double vessel percutaneous coronary angioplasty. $\mathcal{F}$ Am Coll Cardiol 1985;6:1239-44.

24 Roubin G, Redd D, Leimgruber P, Abi-Mansour P, Tate J, Gruentzig A. Restenosis after multilesion and multivessel coronary angiography (PTCA) [abstr]. $₹ \mathrm{Am}$ Coll Cardiol $1986 ; 7: 22$.

25 Libow MA, Leimgruber PP, Roubin GS, Gruentzig A. Restenosis after PTCA in chronic total coronary artery occlusion [abstr]. $\mathcal{f}$ Am Coll Cardiol 1985;5:445

26 Holmes DR Jr, Vlietstra RE, Reeder GS, Bresnahan JF, Peihler JM. Balloon angioplasty for total coronary occlusion not associated with evolving myocardial infarction [abstr]. F Am Coll Cardiol 1986;7:211.
27 Schuler G, Hambrecht R, Schlierf G, Neibauer J, Hauer $\mathrm{K}$, Neumann FJ, et al. Regular physical exercise and low-fat diet. Effects of progression of coronary artery disease. Circulation 1992;86:1-11.

28 Ip JH, Fuster V, Badimon L, Badimon J, Taubman MB, Chesebro JH. Syndromes of accelerated atherosclerosis: Role of vascular injury and smooth muscle cell proliferation. F Am Coll Cardiol 1990;15:1667-87.

29 Stiles CD, Pledger WJ, Tucker RW, Martin RG, Scher CD. Regulation of the Balb/C-3T3 cell cycle effects of growth factors. I Supramol Struct 1980;13:489-99.

30 Jackson CL, Bush RC, Bowyer DE. Inhibitory effect of calcium antagonists on balloon catheter-induced arterial smooth muscle cell proliferation and lesion size. Atherosclerosis 1988;69:115-22.

31 Nomoto A, Hirosumi J, Sekiguchi C, Mutoh S, Yamaguchi I, Aoki H. Antiatherogenic activity of FR34235 (nivaldipine), a new potent calcium antagonist. Effect on cuff-induced intimal thickening of rabbit carotid artery. Atherosclerosis 1987;64:255-61.

32 Clowes AW, Schwartz SM. Significance of quiescent smooth muscle migration in the injured rat carotid smooth muscle migration in the

33 Beatt KJ, Serruys PW, Hugenholtz PG. Restenosis after coronary angioplasty: New standards for clinical studies. f Am Coll Cardiol 1990;15:491-8.

34 Schwarz F, Tillmanns H, Schuler G, et al. Ballondilatation bei instabiler Angina pectoris und akutem Herzinfarkt. Dtsch Med Wochenschr 1987;112: 1973-6.

35 Serruys PW, Luijten HE, Beatt KJ, Geuskens R, De Feyter PJ, Van Den Brand M, et al Incidence of restenosis after successful coronary angioplasty: a time-related phenomenon. Circulation 1988;77:361-71.

36 Schwartz L, Bourassa MA, Lesperance J, Aldridge HE, Kchwartz L, Bourassa MA, Lesperance J, Aldridge HE, Kazim F. Asprin and dipyridamole in the prevention of
restenosis after PTCA. N Engl $₹$ Med 1988;318:1714-9.

37 White $C W$, Knudson M, Schmidt D, et al. Neither ticlopidine nor aspirin-dipyridamole prevent restenosis post PTCA: results from a randomized placebo-controlled multicenter trial [abstr.]. Circulation 1987;76(suppl IV):213. 